\title{
Bewegen gemeten: verschillende cijfers door gebrek aan gouden standaard
}

Sanne de Vries, ${ }^{1}$ Vincent Hildebrandt, ${ }^{1}$ Luuk Engbers, ${ }^{1}$ Karin Hekkert, ${ }^{1}$ Ingrid Bakker ${ }^{1}$

Uit onderzoek komen verschillende, schijnbaar tegenstrijdige, cijfers over de mate van bewegen van Nederlandse bevolkingsgroepen naar voren. Dit belemmert het formuleren en evalueren van beleidsdoelen voor het stimuleren van bewegen. De gevonden verschillen hangen onder meer samen met het ontbreken van een gouden standaard voor het meten van bewegen op verschillende niveaus (nationaal, regionaal, lokaal, individueel), voor verschillende doeleinden (trends monitoren, effecten evalueren, screenen, opstellen van persoonlijke beweegdoelen) en voor verschillende doelgroepen (jeugd, volwassenen, ouderen en chronisch zieken). Als gevolg hiervan wordt er een breed scala aan meetinstrumenten gebruikt waarvan de resultaten onderling niet of slecht vergelijkbaar zijn. Voor het formuleren van heldere beleidsdoelen op het gebied van bewegen en de evaluatie daarvan is het gewenst consensus te bereiken over welke vragenlijsten en/of welke objectieve meetmethoden in Nederland de voorkeur verdienen om het beweeggedrag te meten per niveau, doel en doelgroep en, in het verlengde daarvan, welk ontwikkelingstraject gewenst is om op termijn te komen tot meer valide en betrouwbare meetmethoden.
In het afgelopen decennium heeft er in Nederland een enorme ontwikkeling plaatsgevonden op het gebied van beweegstimulering. Binnen een relatief korte periode is het belang van bewegen voor de gezondheid niet alleen onderkend, maar is ook op grote schaal een actief beweegstimuleringsbeleid in $\mathrm{Ne}$ derland uitgerold. In eerste instantie was er vooral aandacht voor het uitdragen van het belang van bewegen voor de algehele bevolking zoals verwoord in de beleidsnota Sport, bewegen en gezondheid $(2001)^{1}$ van het Ministerie van Volksgezondheid Welzijn en Sport. In deze periode is er een landelijke monitor naar bewegen opgezet binnen het onderzoek Ongevallen in Nederland, sindsdien Ongevallen en Bewegen in Nederland (OBiN) genaamd. Toen in 2005 uit deze monitor naar voren kwam dat het percentage Nederlanders dat aan de beweegnormen voldoet is gestegen sinds 2000 , maar dat voor een aantal specifieke doelgroepen de situatie aanzienlijk minder gunstig was, ontstond de behoefte om het beleid steeds specifieker te formuleren. ${ }^{2}$ Dit heeft er toe geleid dat in het Nationaal Actieplan Sport en Be-

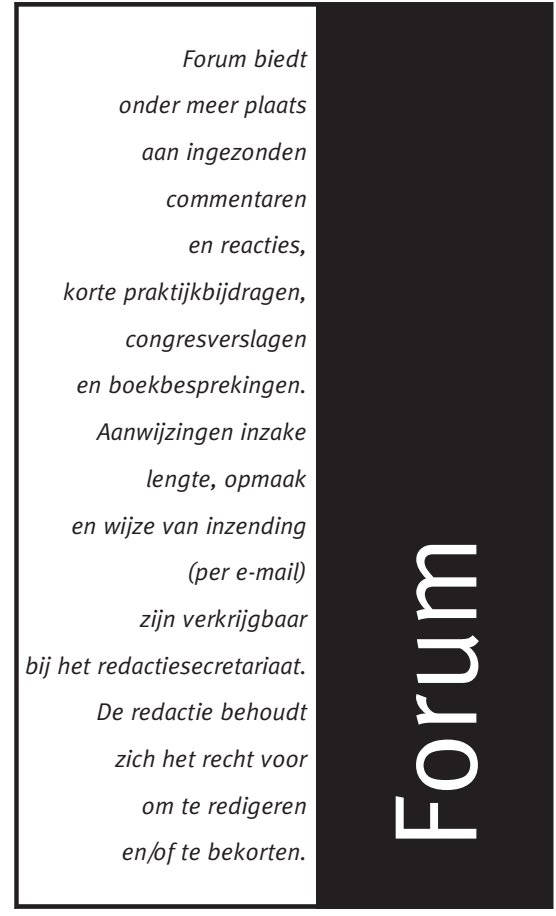

wegen (NASB) ${ }^{3}$ specifiek aandacht wordt besteed aan doelgroepen waar nog aanzienlijke beweegwinst kan worden geboekt, o.a. jongeren, ouderen, chronisch zieken, allochtonen, werknemers in bepaalde beroepsgroepen en mensen met een lage opleiding. Ook op regionaal, lokaal en individueel niveau wordt steeds meer aandacht besteed aan beweegstimulering.

Het actieve beweegstimuleringsbeleid heeft er toe geleid dat er in toenemende mate behoefte is aan gegevens over sport en bewegen. Daarbij ligt het accent op gegevens over de mate waarin wordt voldaan aan de vigerende norm op dit gebied, te weten de Nederlandse Norm Gezond Bewegen (NNGB, zie kader 1).

Tabel 1 Voor- en nadelen van objectieve en subjectieve methoden om sport en bewegen te meten.

\begin{tabular}{|c|c|c|}
\hline Methode & Voordelen & Nadelen \\
\hline $\begin{array}{l}\text { Objectieve meetmethoden } \\
\text { Indirecte calorimetrie }\end{array}$ & kalibratie van meetinstrumenten & $\begin{array}{l}\text { kostbaar, tijdrovend, experts nodig voor uitvoering, geen } \\
\text { natuurlijke meetomstandigheden }\end{array}$ \\
\hline Dubbel gelabeld water & natuurlijke omstandigheden, lange meetperiode & $\begin{array}{l}\text { kostbaar, geen inzicht in beweegpatroon (frequentie, } \\
\text { intensiteit, tijdsduur, type activiteit) }\end{array}$ \\
\hline Hartslagmeters & $\begin{array}{l}\text { gebruiksvriendelijk, relatief goedkoop, grote dataop- } \\
\text { slag, natuurlijke omstandigheden }\end{array}$ & $\begin{array}{l}\text { invloed diverse andere factoren (o.a. stress, koffie, leef- } \\
\text { tijd), variabiliteit in hartslag, comfort en gevoeligheid } \\
\text { borstband }\end{array}$ \\
\hline $\begin{array}{l}\text { Stappentellers en versnellings- } \\
\text { meters }\end{array}$ & $\begin{array}{l}\text { gebruiksvriendelijk, relatief goedkoop, klein, natuur- } \\
\text { lijke omstandigheden }\end{array}$ & $\begin{array}{l}\text { conversie naar energieverbruik, registratiefout bij } \\
\text { bepaalde activiteiten (o.a. fietsen en traplopen) }\end{array}$ \\
\hline \multicolumn{3}{|l|}{ Subjectieve meetmethoden } \\
\hline $\begin{array}{l}\text { Zelfrapportage } \\
\text { (vragenlijsten, dagboekjes, inter- } \\
\text { views) }\end{array}$ & $\begin{array}{l}\text { goedkoop, inzicht in beweegpatroon, bruikbaar voor } \\
\text { grootschalig epidemiologisch onderzoek }\end{array}$ & $\begin{array}{l}\text { afhankelijk van herinnering, conversie naar energiever- } \\
\text { bruik, invloed sociale wenselijkheid, discipline invullen } \\
\text { dagboekjes }\end{array}$ \\
\hline
\end{tabular}


Kader 1 Definitie Nederlandse Norm Gezond Bewegen.

Jeugd (4-18 jaar)

Dagelijks een uur tenminste matig intensieve lichamelijke activiteit ( $\geq 5$ metabole equivalenten (MET)), waarbij de activiteiten minimaal twee maal per week gericht zijn op het verbeteren of handhaven van lichamelijke fitheid (kracht, lenigheid en coördinatie).

Volwassenen (18-55 jaar)

Tenminste een half uur minimaal matig intensieve lichamelijke activiteit ( $\geq 4$ MET) op minimaal 5 dagen per week. Ouderen (55 plus)

Tenminste een half uur minimaal matig intensieve lichamelijke activiteit ( $\geq 3$ MET) op minimaal 5 dagen per week.

In het verlengde hiervan is ook de vraag toegenomen naar valide en betrouwbare methoden voor het meten van sport en bewegen op verschillende niveaus, voor verschillende doelen en doelgroepen. Voor het formuleren en evalueren van beleidsdoelen is het van belang dat informatie over de ontwikkelingen met betrekking tot sport en bewegen zo eenduidig mogelijk is. In de huidige situatie komen echter verschillende, schijnbaar tegenstrijdige cijfers met betrekking tot sport en bewegen naar voren.

In dit artikel wordt aan de hand van een aantal voorbeelden nader ingegaan op verklaringen voor verschillen in cijfers over bewegen, toegespitst op de NNGB. Tevens wordt een voorstel gedaan voor het adresseren van lacunes en knelpunten op dit gebied.

Er zijn verschillende subjectieve en objectieve methoden om sport en bewegen te meten. Onder subjectieve meetmethoden vallen vragenlijsten, dagboekjes en interviews. Voorbeelden van objectieve meetmethoden zijn: dubbel gelabeld water, indirecte calorimetrie, hartslagmeters, stappentellers en versnellingsmeters. Elke methode heeft zowel voor- als nadelen (zie Tabel 1).

Een gouden standaard voor het meten van sport en bewegen bestaat op dit moment niet. Dubbel gelabeld water $\left({ }^{2} \mathrm{H}_{2}{ }^{18} \mathrm{O}\right)$ wordt vaak beschouwd als gouden standaard. Door in urine monsters de afnamesnelheid van ingenomen isotopen ${ }^{2} \mathrm{H}$ en ${ }^{18} \mathrm{O}$ te meten en vervolgens de hoeveelheid geproduceerde kooldioxide te berekenen kan die waarde gebruikt worden als valide maat voor het energieverbruik. Deze methode is echter zeer bewerkelijk en geeft geen inzicht in de frequentie, intensiteit en tijdsduur van sport- en beweegactiviteiten of in het type activiteiten. Bij gebrek aan een gouden standaard wordt in elk onderzoek een keuze gemaakt uit een breed scala aan beschikbare meetinstrumenten, mede afhankelijk van de onderzoeksvraag, de onderzoekspopulatie, de eisen die worden gesteld aan de validiteit en betrouwbaarheid van het meetinstrument en de beschikbaarheid van norm- en referentiewaarden. ${ }^{4,5} \mathrm{Bij}$ deze keuze spelen pragmatische redenen als de beschikbare tijd en het budget echter veelal een grotere rol dan methodologische overwegingen.

Het gebruik van verschillende meetinstrumenten naast elkaar kan leiden tot verschillende uitkomsten die onderling niet of slecht vergelijkbaar zijn. In kader 2 worden hiervan twee voorbeelden gegeven.

De verschillen in kader 2 kunnen slechts gedeeltelijk worden verklaard door verschillen in de sociaaldemografische kenmerken van de onderzoekspopulatie (leeftijd, geslacht, etniciteit, opleidingsniveau, woonomgeving, etc.). De verschillen hangen sterk samen met de manier waarop bewegen is uitgevraagd. Zo is in het onderzoek van Zeijl et al. ${ }^{7}$ de vraag gesteld 'Hoe vaak per week doe je tenminste een uur aan lichaamsbeweging?'. In het onderzoek van Bruijl et al., ${ }^{8}$ Vogelsang et al. ${ }^{9}$ en De Vries et al. ${ }^{10}$ is op

Kader 2 Voorbeelden van verschillende cijfers over de NNGB bij gebruik van verschillende zelfrapportage methoden.

\section{Jeugd}

In 2005 bleek dat slechts 3\% van de kinderen de Nederlandse Norm Gezond Bewegen (NNGB) (kader 1) haalt. ${ }^{6}$ Het ging hier om 6-tot 11-jarige stadskinderen uit aandachtswijken. Uit onderzoek van Zeijl et al. ${ }^{7}$ kwam in hetzelfde jaar naar voren dat $20 \%$ van de 8- tot 12-jarigen de NNGB haalt. In het onderzoek van Bruil et al., ${ }^{8}$ Vogelsang et al. ${ }^{9}$ en De Vries et al. ${ }^{10}$ is daarentegen gevonden dat respectievelijk $80 \%, 97 \%$ en $90 \%$ van de basisscholieren de NNGB haalt. Bij al deze onderzoeken is gebruik gemaakt van verschillende zelfrapportage methoden (dagboekjes en/of vragenlijsten).

\section{Ouderen}

Gegevens van de OBiN enquête laten zien dat in 2005 het percentage Nederlanders tussen de 55 en 64 jaar oud dat voldoet aan de NNGB gestegen was tot $55 \%$ in vergelijking met $44 \%$ in 2001. Het percentage Nederlanders tussen de 65 en 74 jaar dat voldeed aan de NNGB is gestegen van $43 \%$ in 2001 tot $52 \%$ in 2005 en het aantal 75 -plussers dat voldeed aan de NNGB is gestegen van $37 \%$ in 2001 tot $45 \%$ in $2005 .{ }^{11}$ De CBS-POLS enquête laat echter zien dat het percentage Nederlanders in de leeftijd van 55-64 jaar dat voldeed aan de NNGB tussen 2001 (71\%) en 2005 (72\%) veel hoger lag en bovendien nauwelijks was veranderd. Ook het percentage normactieven in de leeftijd van 65-74 jaar vertoonde nauwelijks verandering tussen 2001 (66\%) en 2005 (65\%), even als het percentage 75 -plussers dat voldeed aan de NNGB (van $44 \%$ in 2001 tot $46 \%$ in 2005 ). ${ }^{12}$ 
Kader 3 Voorbeelden van verschillen tussen objectieve en subjectieve methoden om de beweegnorm te meten.

\section{Jeugd}

In 2007 hebben Hekkert et al. ${ }^{13,14}$ de NNGB binnen één onderzoek op drie manieren berekend, op basis van de vraag 'Hoeveel dagen per week heb je tenminste 60 minuten per dag zulke lichaamsbeweging?' (OBiN-vraag voor jeugd), op basis van vragen over transport, schoolsport, sport en buitenspelen (Standaardvraagstelling Bewegen Jeugd) en op basis van een ActiGraph versnellingsmeter. De verschillen in het percentage 7- tot 9-jarige kinderen dat volgens de verschillende methoden aan de NNGB voldeed waren aanzienlijk (20\%, respectievelijk $88 \%$ en $0 \%$ ). ${ }^{13,14}$

\section{Volwassenen}

Uit een Amerikaanse monitor (National Health and Nutritional Examination Survey (NHANES)) kwam naar voren dat $4 \%$ van de volwassenen (20 plus) de beweegnorm haalde als werd uitgegaan van ActiGraph versnellingsmeter gegevens en $51 \%$ als werd uitgegaan van zelfgerapporteerde gegevens. ${ }^{15}$

basis van een optelsom van meerdere vragen over de frequentie en duur van actief transport, schoolsport, sport en buitenspelen nagegaan of een kind al dan niet aan de NNGB voldeed. Deze vragen zijn ook wel bekend onder de naam Standaardvraagstelling Bewegen Jeugd uit de Lokale en Nationale Monitor Jeugdgezondheid (www.monitorgezondheid.nl). Het onderzoek van De Vries et al. ${ }^{6}$ is gebaseerd op een beweegdagboekje dat de kinderen samen met hun ouders een week lang bijhielden (vergelijkbaar met het vijfjaarlijkse tijdsbestedingonderzoek (TBO)). Kleine verschillen in vraagstelling kunnen zo heel verschillende resultaten opleveren. Hierin speelt mee dat de operationalisering van het begrip 'matig intensief' in de NNGB (dat voor elke leeftijdscategorie ook nog eens anders is) in vragenlijsten bijzonder lastig is en eigenlijk alleen met objectieve meetmethoden goed afgegrensd kan worden. Dat is waarschijnlijk één van de belangrijkste redenen waarom over het algemeen een lager percentage respondenten de NNGB haalt als het beweeggedrag objectief gemeten wordt in plaats van subjectief (zie kader 3).

Andere factoren die een rol kunnen spelen bij verschillen in cijfers over bewegen zijn onder andere:

- de definitie en operationalisering van de NNGB; ${ }^{16}$

- de wijze van afname van vragenlijsten (face-to-face, telefonisch, schriftelijk, internet); ${ }^{17,18}$

- de gehanteerde referentieperiode bij vragen over sport en bewegen (afgelopen twaalf maanden, afgelopen maand/ week, normale week);
- de seizoensinvloeden (zomer versus winter) die invloed hebben op het gemeten gedrag;

- de wijze van steekproef trekking (panel versus random steekproef) en de daarmee gepaard gaande verschillen in de sociaaldemografische kenmerken van de steekproef;

- het gebrek aan afstemming tussen onderzoekers over de wijze van analyse en interpretatie van de data (hoe wordt omgegaan met missende of extreme waarden, welke afkap- of omrekenwaarden worden gebruikt, etcetera).

In dit artikel is een aantal verklaringen aangedragen voor verschillen in cijfers over bewegen. Het ontbreken van een gouden standaard voor het meten van sport en bewegen is hier een van. De complexiteit van de NNGB ten aanzien van de vereiste minimale intensiteit van bewegen (de operationalisering van het begrip 'matig intensief') is een andere verklaring, temeer daar juist de intensiteit van bewegen lastig met vragenlijsten is te meten. En deze vragenlijsten domineren nu juist van oudsher het pallet aan meetmethoden om sport en bewegen op nationaal niveau te monitoren omdat zij relatief eenvoudig en goedkoop zijn in te zetten en weinig specifieke expertise lijken te behoeven. In 2005 hebben TNO en het RIVM een expertmeeting georganiseerd om consensus te bereiken over het monitoren van sport en bewegen in $\mathrm{Ne}$ derland door middel van vragenlijsten. ${ }^{19,20}$ Tevens heeft GGD Nederland in
2005 twee standaardvraagstellingen vastgelegd om het beweeggedrag van jeugd, volwassenen en ouderen te meten op regionaal en lokaal niveau (www.monitorgezondheid.nl). Het is echter de vraag of vragenlijsten die ingezet worden voor het monitoren van trends op populatieniveau ook bruikbaar zijn voor het evalueren van interventies, het schatten van het energieverbruik op individueel niveau, het screenen van mensen met bewegingsarmoede of het opstellen van een beweegprogramma op maat. Het lijkt erop dat de huidige vragenlijsten niet altijd specifiek of gevoelig genoeg zijn om verandering te kunnen meten of om mensen met bewegingsarmoede te kunnen identificeren. ${ }^{8,10,21}$ Bovendien zijn vragenlijsten volledig afhankelijk van de subjectieve inschatting van de respondent, welke in grote mate afhankelijk is van geheugen, tijdsgewricht, persoonskenmerken en geldende sociale normen en waarden. Dit pleit er voor in de komende jaren de aandacht te verleggen van vragenlijstontwikkeling en -validering naar de ontwikkeling van objectieve methoden om het beweeggedrag te meten. ${ }^{22}$ Deze bieden mogelijk een betere waarborg voor valide en betrouwbare data. Daarbij lijkt de tijd rijp om hierin te investeren: de snelle technologische ontwikkelingen maken het mogelijk om het beweeggedrag steeds nauwkeuriger en goedkoper objectief te meten, bijvoorbeeld met geavanceerde hartslagmeters, stappentellers en versnellingsmeters. Door nauwkeurige Global Positioning Systems (GPS) aan deze instrumenten te koppelen is het tegenwoordig eveneens mogelijk de beweeglocatie van de activiteiten te registreren.

Het is wenselijk om op korte termijn 
meer consensus te bereiken tussen deskundigen en beleidspartijen over de instrumenten die bij voorkeur gebruikt dienen te worden voor het meten van bewegen op verschillende niveaus (nationaal, regionaal, lokaal, individueel), voor verschillende doeleinden (trends monitoren, effecten evalueren, screenen, opstellen van persoonlijke beweegdoelen) en voor verschillende doelgroepen (jeugd, volwassenen, ouderen en chronisch zieken). Hierbij dient te worden vastgesteld in welke gevallen kan worden volstaan met zelfrapportage methoden en in welke gevallen objectieve methoden wenselijk zijn. In geval van zelfrapportage methoden, verdient het aanbeveling verdere consensus te bereiken over de vraag welke vragenlijst voor welk doel en in welke doelgroepen de beste keuze is. Tevens dient onderzocht te worden in hoeverre er 'conversiesleutels' zijn te ontwikkelen om resultaten verkregen met verschillende meetinstrumenten toch te kunnen vergelijken. In geval van objectieve methoden voor het meten van bewegen, verdient het aanbeveling na te gaan welke thans beschikbare methoden veelbelovend zijn en verder ontwikkeld moeten worden. Daarbij is van belang de verschillende, eerder genoemde, doelen waarvoor meetmethoden kunnen worden ingezet goed te onderscheiden, omdat de eisen en randvoorwaarden waaraan een meetmethode moet voldoen per doel en doelgroep kunnen verschillen.

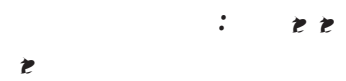

There is conflicting information on the physical activity level of different Dutch population groups. The differences can partly be explained by the lack of a gold standard for assessing physical activity at different levels (i.e., national, regional, local, and individual), for different epidemiological purposes (e.g., trend monitoring, effect evaluation, and screening), and in different target populations (e.g., youth, adults, and elderly). In order to support national policymaking on physical activity, it is essential to reach consensus on which question- naires and/ or objective instruments are the preferential method to assess physical activity per level, purpose, and target population.

Keywords: physical activity, assessment methods, questionnaire

1. Ministerie van Volksgezondheid Welzijn en Sport. Nota Sport, bewegen en gezondheid. Naar een actief kabinetsbeleid ter vergroting van de gezondheid door en bij sport en beweging. Den Haag: Ministerie van VWS, 2001.

2. Ooijendijk WTM, Hildebrandt VH, Hopman-Rock M. Bewegen in Nederland 2000-2005. In: Hildebrandt VH, Ooijendijk WTM, Hopman-Rock M (red). Trendrapport Bewegen en Gezondheid 2004/2005. Leiden: De Bink, 2007: 9-36.

3. Ministerie van Volksgezondheid Welzijn en Sport, Verenging van Nederlandse gemeenten, NOC*NSF. Kaderstellende afspraken Impuls Nationaal Actieplan Sport en Bewegen. Den Haag: Ministerie van VWS, 2008.

4. Vrijkotte S, Vries SI de, Jongert MWA.

Fitheidstesten voor de jeugd. Leiden: TNO Kwaliteit van Leven, 2007.

5. Vries SI de, Pronk MG, Hopman-Rock M, Jongert MWA. Assessing physical activity in children and adolescents. A review of different methods. Leiden: TNO Preventie en Gezondheid, 2003.

6. Vries SI de, Bakker I, Overbeek K van, Boer ND, Hopman-Rock M. Kinderen in prioriteitswijken: lichamelijke (in)activiteit en overgewicht. Leiden: TNO Kwaliteit van Leven, 2005.

7. Zeijl E, Crone M, Wiefferink K, Keuzekamp $S$, Reijneveld $M$. Kinderen in Nederland. Den Haag: SCP, Leiden: TNO Kwaliteit van Leven, 2005.

8. Bruil J, Dijkstra NS, Jacobusse GW et al. Handleiding Vragenlijsten Schoolgezondheid Basisonderwijs “Wat doe jij voor je gezondheid?” Leiden: TNO Preventie en Gezondheid \& GGD Nederland, 2004.

9. Vogelsang $K$, Vermeeren $M$, Hoef RTH van de et al. Gezond bewegen in groep 7 en 8 . Tilburg: Fontys Sporthogeschool, 2006.

10. Vries SI de, Overbeek K van, Jongert MWA et al. Evaluatie Scoren voor Gezondheid. Leiden: TNO Kwaliteit van Leven, 2007.

11. Ooijendijk WTM, Hildebrandt VH, Chorus AMJ. Bewegen in Nederland 2000-2007. In: Hildebrandt VH, Ooijendijk WTM, Hop-
man-Rock M (red). Trendrapport Bewegen en Gezondheid 2006/2007. Leiden: De Bink, 2008: 9-42.

12. Wendel-Vos GCW, Frenken F, Schuit AJ. Het beweeggedrag in Nederland 20012006. In: Hildebrandt VH, Ooijendijk WTM, Hopman-Rock M (red). Trendrapport Bewegen en Gezondheid 2004/2005. Leiden: De Bink, 2007: 37-52.

13. Hekkert KD, Vries SI de, Bakker I. Overweight and physical activity in children; Comparison between native children and children from a non-western ethnic origin living in a disadvantaged neighbourhood in Maassluis. Stageverslag. Leiden: TNO Kwaliteit van Leven, 2007.

14. Hekkert KD, Vries SI de, Bakker I. Meten van lichamelijke activiteit bij kinderen: gebruik van verschillende meetmethoden levert zeer uiteenlopende resultaten op. Tijdschr Gezondheidswet 2008; 68 (2): 36.

15. Trioano RP, Berrigan D, Dodd KW et al. Physical activity in the United States measured by accelerometer. Med Sci Sports Exerc 2008;40:181-8.

16. Vries SI de, Hopman-Rock M, Bakker I, Mechelen $W$ van. Meeting the 6o-min physical activity guideline: effect of operationalization. Med Sci Sports Exerc 2009:41:81-6.

17. Greene J, Speizer H, Wiitala W. Telephone and Web: Mixed-Mode Challenge. Health Services Res 2008;43:230-48.

18. Leeuw ED de. To mix or not to mix data collection modes in surveys. JOS 2005; 21(2):233-55.

19. Ooijendijk WTM, Wendel-Vos W, Vries SI de. Advies consensus vragenlijsten sport en bewegen. Leiden: TNO Kwaliteit van Leven, 2007.

20. Ooijendijk WTM, Wendel-Vos W, Vries SI de. Reader consensus vragenlijsten sport en bewegen. Leiden/ Bilthoven: TNO Kwaliteit van Leven/ RIVM, 2005.

21. Singh A. Effectiveness of a school-based weight gain prevention programma. Proefschrift. Amsterdam: Vrije Universiteit, 2008.

22. Vries SI de, Schermers $P$, Gielis F, Engbers $L H$. Objectief meten bewegen; State of the art. Engbers LH, Hildebrandt VH, red. Leiden: TNO Kwaliteit van Leven, 2008.

\section{CORRESPONDENTIEADRES \\ Drs. Sanne de Vries, TNO Kwaliteit \\ van Leven, Postbus 2215, 2301 CE Leiden, e-mail: sanne.devries@tno.nl}

